\title{
Sainte-Marguerite-La-Figère, Malarce-sur-Thines
}

Mines du Colombier

\section{Flavien Perazza et Marie-Christine Bailly-Maître}

\section{(2) OpenEdition}

Édition électronique

URL : http://journals.openedition.org/adlfi/3462

ISSN : 2114-0502

Éditeur

Ministère de la culture

Référence électronique

Flavien Perazza et Marie-Christine Bailly-Maître, « Sainte-Marguerite-La-Figère, Malarce-sur-Thines », ADLFI. Archéologie de la France - Informations [En ligne], Rhône-Alpes, mis en ligne le 01 mars 2009, consulté le 03 mai 2019. URL : http://journals.openedition.org/adlfi/3462

Ce document a été généré automatiquement le 3 mai 2019.

(C) Ministère de la Culture et de la Communication, CNRS 


\title{
Sainte-Marguerite-La-Figère, Malarce-sur-Thines
}

\author{
Mines du Colombier
}

Flavien Perazza et Marie-Christine Bailly-Maître

\section{Identifiant de l'opération archéologique : 10007}

Date de l'opération : 2009 (PT)

1 Les chantiers miniers de la concession du Chassezac sont regroupés en trois secteurs principaux de la rive ardéchoise: La Rouvière (comm. Ste-Marguerite-Lafigère), le Colombier (comm. Ste-Marguerite-Lafigère et Malarce-sur-la-Thines), le Vert (comm. Thines).

2 Les campagnes menées en 2003, 2004 et 2007 ont permis d'inventorier un ensemble de vestiges (relevé topographique, localisation GPS) correspondant à des chantiers extractifs à ciel ouvert et souterrains et deux ateliers de concassage du minerai, le tout calé entre le $\mathrm{XI}^{\mathrm{e}}$ s. et le XIII' s.

3 Au cours de l'été 2009, une opération de mise en sécurité a été conduite sur les chantiers modernes et médiévaux, à la demande de la DRIRE, ce qui équivaut à la destruction des vestiges (bétonnage des têtes de puits et des entrées de galeries, effondrement des bords des dépilages, remblaiement des chantiers par éclatement des parois). Une courte opération préventive a eu lieu au printemps 2009; elle a été conduite par Iker Archéologie et Jérôme Girard en était le responsable. De sorte que la campagne 2009 a été consacrée à une reprise des prospections de surface afin de préparer les nouvelles programmations scientifiques.

4 Plusieurs percuteurs pour le concassage du minerai et des vestiges bâtis en rive droite du Colombier ont été découverts: cabanons, espaces enclos de quatre murs (bâtiment?), murs isolés, mais regroupés sur un espace réduit, terrasse identique à celle qui portait un des deux ateliers, en rive gauche. Il ne s'agit en aucun cas de terrasses de cultures. 
5 L'hypothèse de travail est de situer, sur cet épaulement de colline, l'emplacement des ateliers de traitement du minerai en lien avec les chantiers mitoyens.

6 Les prochaines campagnes seront consacrées à cette thématique.

7 Bailly-Maître Marie-Christine, Perazza Flavien

INDEX

Thèmes : atelier, cabane, enclos, mine, minerai, percuteur

Index chronologique : XIe siècle apr. J.-C., XIIe siècle apr. J.-C., XIIIe siècle apr. J.-C.

operation Prospection thématique (PRT)

Index géographique : Rhône-Alpes, Ardèche (07), Sainte-Marguerite-Lafigère

\section{AUTEURS}

FLAVIEN PERAZZA

association GEMA

MARIE-CHRISTINE BAILLY-MAÎTRE

CNRS 